\title{
The Mammography Screening Controversy: Who and what is heard in the press?
}

Sonya Charles

Cleveland State University, s.charles07@csuohio.edu

Margaret Holmes-Rovner

Follow this and additional works at: https://engagedscholarship.csuohio.edu/clphil_facpub

Part of the Bioethics and Medical Ethics Commons, Ethics and Political Philosophy Commons, and the Feminist Philosophy Commons

How does access to this work benefit you? Let us know!

\section{Publisher's Statement}

This is an Author's Accepted Manuscript of an article published in Patient Education and Counseling, 2003, available online at http://www.pec-journal.com/article/

s0738-3991(02)00167-2/abstract

\section{Original Citation}

Holmes-Rovner, M., \& Charles, S. (2003). The mammography screening controversy: who and what is heard in the press?. Patient Education And Counseling, 51(Diabetes Education and Quality of Life), 75-81. doi:10.1016/S0738-3991(02)00167-2

This Article is brought to you for free and open access by the Philosophy \& Comparative Religion Department at EngagedScholarship@CSU. It has been accepted for inclusion in Philosophy \& Comparative Religion Department Faculty Publications by an authorized administrator of EngagedScholarship@CSU. For more information, please contact library.es@csuohio.edu. 


\title{
The mammography screening controversy: who and what is heard in the press?
}

\author{
Margaret Holmes Rovner ${ }^{\mathrm{a}, *}$, Sonya Charles ${ }^{\mathrm{b}}$ \\ ${ }^{\mathrm{a}}$ Department of Medicine, B213 Clinical Center, Michigan State University, East Lansing, MI 48824, USA \\ ${ }^{\mathrm{b}}$ Department of Philosophy, Michigan State University, East Lansing, MI 48824, USA
}

\section{Introduction}

Gotzsche and Olsen published a controversial meta-analysis of the efficacy of screening for breast cancer with mammography in the Lancet in 2000 [1]. The authors concluded that, "Screening for breast cancer with mammography is unjustified... There is no reliable evidence that screening decreases breast-cancer mortality." Since England, and most of Europe and North America support mammography programs for breast-cancer screening, the study was instantly controversial. Much of the controversy centered on the study methods. Eight randomized trials met the quality criteria, forming the basis for the meta-analysis. Four of the eight studies were found by the authors to have inconsistencies in the number of women randomized. The two individually randomized trials found no effect of screening on breast-cancer mortality, or on total mortality. The Commentary article that accompanied the meta-analysis article in the Lancet argued that the quality of the excluded trials was high, and that recent results of a central study, the Swedish trial included by Gotzsche and Olsen, actually showed a reduction in the relative risk of death from breast

\footnotetext{
* Corresponding author. Tel.: +1 517353 5197; fax: +1 5174329471. E mail address: mholmes@msu.edu (M. Holmes Rovner).
}

cancer of 0.81 (ages 4569 years). The technical and the policy aspects of the Gotzsche and Olsen study proved to be highly controversial.

While there is good evidence that screening identifies breast cancers early, there is less evidence of a survival benefit. Establishing the effectiveness of mammography is challenging, in part because the procedure is for seemingly health women, for whom the criteria for doing it should be clear cut to justify a public programmme. Predicting who will benefit, and who will suffer more harm than good, is impossible at the individual level. For these reasons, it is difficult for members of the public to understand the issues and make personal health choices. How the press presents medical controversy plays a key role in shaping personal choices and policy debates. The mammography case offers a particularly focused opportunity for analysis, due to the impact of a single article that challenged medical and health service policy.

Gotzsche and Olsen published their meta-analysis, "Is screening for breast cancer with mammography justifiable?" in the Lancet in January 2000 [1]. Given the level of policy support across the UK, Europe, and North America screen for breast cancer using mammography, the possibility that scientific evidence may not support such a policy was highly newsworthy. In this case study, we describe how the 
controversy was reported, and whose language was used to explain the issues to the public. While the scientific controversy remains, the case provides an opportunity to examine the role of the press in supporting public access to evidence about health care.

\section{Methodology}

The analysis began from two perspectives. The purpose of the simple content analysis was to summarize the content and structure of the articles. The content categories to be investigated were: (1) what the press presented as the important issues in whether mammography should or should not be performed, (2) what sources of evidence were chosen to represent both sides, and (3) what story lines reporters used to organize the information. A second perspective was the consumer choice analysis. That perspective led us to look for information that would be useful to patients in making an informed choice for themselves. The elements looked for were: (1) pros and cons of screening versus not screening for a population and for an individual, and (2) effectiveness of treatment (should breast cancer be identified) under screening and no screening conditions. Pros and cons looked for were likelihood of finding cancer, and likelihood of dying of cancer, and the patient concerns that are generated by false positive and false negative mammography results. Since the Gotzsche and Olsen meta-analysis claimed to demonstrate that a screening test was not justified, in terms of the numbers of lives saved with and without screening, we began expecting these to be the core of the press reporting.

The data source was a comprehensive set of newspaper articles collected by the National Health Service BreastCancer Screening Programme covering the 10 days following the January 7, 2000 press release [2]. This included 148 articles in 113 different newspapers from across the UK. All the newspapers reviewed are listed in Appendix A. In a hand search, screening programme staff reviewed all the papers each day during the period and clipped the full text of the article. The data were collected for the purpose of tracking the press coverage. They were made available for independent analysis at the request of the investigators.

The first step was for both authors to read all the articles. The second step was to develop a set of categories for the simple content analysis and the consumer choice analysis. The latter produced so little codable data that it was abandoned. The answer to the first question (what are the issues) was resolved by consensus of the investigators. The main issue was, "Should the government abandon screening?" The second question (sources of evidence) was infrequently the scientific evidence discussed in the meta-analysis. Each article had at least one reference to an expert. For that reason, the content category became, who was quoted, or "proportion of quotations by source." This was a simple count of which authorities were quoted. The total list was five. Each article was then coded according to the presence or absence of a quotation from each of the authorities. On the first read through, the first author made a list of main themes (those reported as headlines or discussed in the first paragraph of the news article). Those were: (1) Is the Government wasting time or money? (2) Does the mammography controversy have budget cutting implications, or is it an attempt by the Government to save money in the budget? (3) Has anyone been injured? (4) Has anyone been saved? (5) Would eliminating mammography discriminate against women or the elderly? The second author (SC) developed a coding system to count mentions of these themes. However, she found additional themes found additional pieces of information that journalists supplied to support the screening programme. These, again, were not found in the Lancet article, but supplied the local context for the press. The screening programme related information cited frequently were: (1) amount of money spent, (2) numbers of women affected, and (3) pending Government decisions to expand breast-cancer screening. Articles were coded as present or absent for each of the three programmme items.

The specific core content cited by the press to evaluate the two sides of the argument about whether to breast cancer saved lives were largely not those found in the Gotzsche article. The data cited most frequently were: (1) numbers of cancers found, (2) size of tumors at detection, (3) numbers of lives saved as quoted in screening programmed documents (not the Gotzsche article), and (4) mortality rates for the nation. The most frequently cited information item from the Lancet was not from the Gotzsche article, but from the opposing commentary by Dr. Harry de Koning, of the Rotterdam Department of Public Health in the Netherlands. Dr. de Koning was quoted as saying that Gotzsche and Olsen have ignored the fact that other factors probably have a more important part in lowering the mortality rate through screening. Articles were coded for presence or absence of each of these screening effectiveness items.

After the codes were developed, a sample was tested for reproducibility by the two authors. Once agreement was confirmed on the first 10 articles, all were subsequently coded by the second author (SC), and checked by the first author. A text unit for the purposes of counting presence or absence of content items was the entire article, defined as any text found on the same page, or a continuous flow of dialogue if the article carried over to another page. This was to avoid double counting sources. The length of the text cited was not calculated. We excluded articles that were exact duplicates, articles unrelated to the Lancet article, articles that were exclusively editorials or commentaries, and letters to the editor.

Initially, the entire set of articles were coded as one group. However, as coding progressed, the frequencies suggested that a shift in emphasis occurred over time. The shift appeared to be roughly between the first and second weeks of coverage. We, therefore, divided articles into two groups chronologically. Wave 1 included articles that appeared the Friday after the press release, January 7 , 
2000, through the following Sunday, January 9, 2000. Wave 1 contained the initial bolus of information reporting and interpretation. Wave 2 included articles that appeared during the second week (10 21 January), when the January 8, 2000 issue would have been widely available to the medical expert community. All articles were read a second time and coded. Since most were short, we coded specific information types as absent or present. We did not estimate the proportion of the article taken up by a specific topic. We identified five primary sets of stakeholders in the controversy: the original authors, the author of the invited commentary, medical Lancetexperts, breast-cancer advocates, and screening programme spokespersons. Phrases representing the original authors were coded as author quotes if they were direct quotations from the press release, the original article, or a recent interview in which they discussed the results of the article [3]. Invited commentary in the Lancet referred to the commentary in the same issue by Koning [4]. A non-author expert was any cancer researcher or physician working in a cancer unit. Advocates were any representatives of cancer advocacy or charity groups. Finally, screening programme spokespersons included any quote from a public health minister, or other official working with the screening programme at a national or local level.

The content categories were: (1) stakeholder sources quoted, and (2) information types reported. Information types differentiate between personal interest stories about individual women who had undergone mammography, and technical aspects of screening or treatment, and statistics about the screening programme. Technical aspects included comments about methods (i.e. randomisation), differences in study subject characteristics, and other aspects of the design and execution of the meta-analysis. Lastly, we coded use of any data about the current screening programme, including screening rates, breast-cancer incidence and mortality under present screening policies, money spent, and claims to lives saved. Money spent on the screening programme included references to the amount of money spent by the UK National Health Service per year and estimates of expenditures per person.

\section{Results}

\subsection{Stakeholders quoted}

A shift occurred from Wave 1 to Wave 2, in the proportion of articles that included author or commentary direct quotes.

Wave 1 articles included a greater proportion of quotes from all stakeholders except the screening programme. Wave 2 articles were more likely to cite the screening programme. Articles including quotes from the original authors decreased from 74 to $30 \%$ in the second week following publication of the Lancet article (Wave 2). All except two or three quotations were from the original press release or article. Almost all were the same quote,
Table 1

Proportion of quotations by source

\begin{tabular}{lcc}
\hline & $\begin{array}{l}\text { Wave 1 } \\
(\text { January 7 9) }\end{array}$ & $\begin{array}{l}\text { Wave 2 } \\
\text { (January 10 21) }\end{array}$ \\
\hline Original authors & $77(74 \%)$ & $13(30 \%)$ \\
Reference to Koning & $43(41 \%)$ & $4(9 \%)$ \\
Expert quote & $55(53 \%)$ & $12(27 \%)$ \\
Advocate quote & $50(48 \%)$ & $5(11 \%)$ \\
Screening programme quote & $56(54 \%)$ & $28(64 \%)$ \\
Total articles & 104 & 44 \\
\hline
\end{tabular}

"Screening for breast cancer with mammography is unjustified" [5]. As indicated in Table 1, there was a shift in Wave 2 toward quoting the screening programme officials.

\subsection{Information type presented}

Use of testimonials increased in Wave 2, while technical aspects, such as whether the reviewed studies were properly randomized, decreased, as did inclusion of data about the screening programme (Tables 2 and 3 ).

References to numbers of cancers found, tumor size, lives saved, and mortality rates were similar across waves. Number of cancers found was given either as average per year or the absolute number in a specific year was given. Size of tumors was reported either as "too small to be felt by hand" or was given in millimetres. Mention of tumor size at detection was rare in both waves. Number of lives saved was reported as either the average per year, or an estimate of lives saved over the first decade (since screening began).

Table 2

Information type

\begin{tabular}{lcl}
\hline & $\begin{array}{l}\text { Wave 1 } \\
(\text { January 7 } 9)\end{array}$ & $\begin{array}{l}\text { Wave 2 } \\
(\text { January 10 21) }\end{array}$ \\
\hline Testimonials & $13(13 \%)$ & $16(36 \%)$ \\
Technical aspects & $62(60 \%)$ & $17(39 \%)$ \\
Total articles & 104 & 44 \\
\hline
\end{tabular}

Table 3

Information cited about the screening programme

\begin{tabular}{lcc}
\hline & $\begin{array}{l}\text { Wave 1 } \\
\text { (January 7 9) }\end{array}$ & $\begin{array}{l}\text { Wave 2 } \\
\text { (January 10 21) }\end{array}$ \\
\hline $\begin{array}{l}\text { Programme related } \\
\text { Money spent }\end{array}$ & $61(59 \%)$ & $6(14 \%)$ \\
$\quad$ Number of women involved & $17(16 \%)$ & $15(34 \%)$ \\
Comments about expanding & $48(46 \%)$ & $7(16 \%)$ \\
$\quad$ the programmme & & \\
Effectiveness & $35(37 \%)$ & $12(27 \%)$ \\
$\quad$ Number of cancers found & $8(8 \%)$ & $5(11 \%)$ \\
$\quad$ Size of tumor & $27(26 \%)$ & $10(23 \%)$ \\
$\quad$ Number of lives saved & $35(37 \%)$ & $15(34 \%)$ \\
$\quad$ Mortality rates & $22(21 \%)$ & $0(0 \%)$ \\
$\quad$ Koning quote (about & & \\
$\quad$ mortality rates) & 104 & 44 \\
$\quad$ Total articles & &
\end{tabular}


How "lives saved" was determined was not given. Mortality was given either as the decline in mortality from breast cancer (overall or per year) or current death rates from cancer. The most common estimate was a $14 \%$ drop in mortality from 1989 to 1998 [6] as well as references to statistics to be released later in the year that would demonstrate a "significant reduction in mortality from breast cancer" [7]. Many articles quoted the de Koning commentary, "In the UK there has been a clear reduction in breast-cancer mortality due in part to screening" [8].

In Wave 2, there were fewer references to money spent or to a possibility of expanding the programme. Per year estimates of the amount of money spent on the screening programme ranged from $£ 36$ to 42 million. References to the amount of money spent on the screening programme represented the most dramatic decrease from the first Wave 1 (59\%) to Wave 2 (14\%). The direct quote from de Koning about falling mortality rates disappeared in Wave 2. Wave 1, in general, focused on the controversy and the radical claims of Goetzsche and Olson; Wave 2 tended to reaffirm support for the current screening programme, including patient testimonials and general information about the screening programme.

\subsection{Article structure and focus}

The typical structure for a Wave 1 article was a "point/ counterpoint". The opening typically announced the "controversial" Lancet article followed by a brief description of the findings (e.g. mammography "unjustified," previous studies lacked proper randomisation). This was followed by a counterpoint (e.g. citation of the "dismay" expressed by cancer advocates and experts). While some included quotes from experts who were critical of the screening programme, most included only positive quotes in this section. The dominant message in this section urged women to ignore the study and continue to attend screening appointments. Many also expressed "fear" that women would quit going for screenings. Following the point/counterpoint, most articles (59\%) included description of expenditures per year on the NHS screening programme. This was frequently followed by a brief comment about support for or criticism of the programme. For example, "Supporters of the programme argue that the cost is worthwhile as it saves lives and there are strong moves to extend the age limit. Some suggested that the money would be better spent improving treatment for breast cancer and searching for new therapies" [9]. Sometimes, this statement was supported with statistics or expert quotes, but more often it was not. Finally, the articles usually ended with either more details about the Lancet article or some positive quote about screening.

In contrast, Wave 2 articles focused more on testimonials or general information about the current screening programme. The format was less uniform, but generally adopted one of these foci. Testimonials frequently included detailed accounts of personal experience with cancer and screening sometimes including general statistics about the current screening programme. Some featured not personal experience, but quotations from opinion leaders, celebrities or experts who "urged" women to continue screening or simply argued for why screening "works" or is important. Theoretical arguments they gave for why women should participate in screening included: it can detect cancers too small to be felt by hand, better chance of recovery, spares women disfiguring surgery, etc. The articles in Wave 2 also usually included a few details from the Lancet article followed by quotes from experts and/or statistics about the current screening programme. Information about the screening programme tended to shift from an emphasis in Wave 1 on the amount of money spent to an emphasis in Wave 2 on the number of women screened (and presumably helped or re-assured as the articles put it).

The shift in focus and structure of Wave 1 (point/counterpoint) and Wave 2 (testimonials/support for the screening programme) was accompanied by an increase in quotes from the screening programme of $10 \%$ and a decrease in data about the screening programme of $15 \%$. In Wave 1 , writers cited advocates and non-author experts as the authority; in Wave 2, the screening programme was cited as the authority. By the second week (Wave 2), the data shifted, in context of support for the screening programme, to tumor size on detection and numbers of women screened.

A final structural issue is that of who are the implied parties to the debate. The answer seems to be that the press cast it as an internal argument among experts that the public could not join. An exception is found in several quotes from experts in Wave 1 articles. These are instructive: "There are flaws in the way it [Goezsche's article] is written. For example, many of the studies looked at are very old. Mammography techniques have improved greatly in recent years" [10], and "... a statistically significant difference in age is not necessarily study significant or a serious bias in screening trials" [11].

These experts try to make the elements of the controversy accessible to the reading public. However, it should also be noted that these more descriptive quotations were mostly found in scientific journals rather than in the mainstream press.

\section{Conclusions}

The discussion in the press of this complicated and provocative meta-analysis was conducted in both waves of articles within a framework fairly typical of discussions of medical news. What is newsworthy is the frequency of the "medical breakthroughs" and human interest stories of how a life was saved. This approach is extended (and further polarized) by the point/counterpoint approach of citing experts and advocates who are either for or against the status quo of treatment policy or programme policy. What 
this approach does not do is deal with medical uncertainty. While the public is accustomed to scandal (i.e. "getting dirt" on ministers, doctors, and other participants in the health care arena), this approach does not ultimately support evidence-based patient decision-making or evidence-based policy. If the public is to become accustomed to making personal health care decisions that reflect their own preferences and a realistic understanding of their chances of benefit or harm with and without medical intervention, they need a different kind of information. Nowhere in the reporting of the coverage of the Gotzsche and Olsen article, does a newspaper include in the background information that $90 \%$ of positive mammograms are normal breasts (e.g. "false positives") that must be investigated further because mammography is not perfectly diagnostic [12].

An immediate concern about presenting medical uncertainty to the public is whether the average reader can understand probabilistic information. The evidence to date from randomized studies of individual patient decisionmaking suggests that they can $[13,14]$, and that dealing with uncertainty does make patients more anxious. Studies of patient attitudes toward medical information show universally that patients want information, whether or not they want to share in decision-making [15].

How should false negative and false positive laboratory test results be discussed with patients? How should the policy question of whether mammography is effective be discussed? We suggest that patients be introduced to background information about mammography, the incidence of breast cancer, and the mortality of screened and unscreened patients. This would require introducing ideas with which many clinicians are uncomfortable, like false positive and false negative rates and negative and positive predictive power. False positives could be framed as "excess biopsies"; false negatives could be framed as "false reassurance" rates. This would allow discussion of issues of the following type:

- What will happen if a patient is not screened?

- What are the alternatives for protecting oneself from cancer?

- Are there any potential harms from screening and followup, and how often do they occur?

One of the issues highlighted by this controversy is a subtle one about who are the parties to the scientific argument. We have suggested that the media cast the argument in this case as being between scientists. The subtle implication of this approach is that the public cannot understand the issues. If health care discussion is to become less paternalistic and include the patients, policy-makers, and the experts, then all must be party to the discussion. One ultimate benefit of introducing patients to false results from mammography is that the public and policy-makers may be able to accept the limitations of technologies and not over react in either a positive or a negative fashion. Given the continuing mammography controversy [16], health professionals and the press now have the opportunity to pioneer a new approach in the context of the breast-cancer screening controversy.

\subsection{Practice implications}

How can clinicians address this new educational challenge among patients who may have been introduced to the mammography debate by the press? They will need to explain that (1) mammograms have never given $100 \%$ perfect information regarding the presence or absence of breast cancer, (2) why the inherent uncertainty resulting from laboratory findings is generating a policy debate about whether national health services should provide mammography, and (3) whether the debate should influence individual patient decisions about mammography. This challenge is likely to become increasingly prevalent, as screening tests like mammography, and prostate specific antigen for prostate cancer continue to be debated. We suggest that clinicians confront this challenge by explaining the concepts of false results to patients, and explaining that they are not mistakes, but an inevitable characteristic of diagnostic tests. Educating patients about this new, and potentially disturbing, idea should, ultimately, improve patients' ability to make informed decisions screening and treatment choices.

\section{Acknowledgements}

This study was begun during Dr. Holmes-Rovner's sabbatical at the Institute for Health Sciences, Oxford, and the Pickner-Institute Europe, with partial support of the Nuffield Trust. The authors thank Dr. Muir Gray and the staff of the National Screening Programme for providing the source document newspaper clippings for independent analysis. The findings have not been reviewed by the Programme and represent only the views of the authors.

\section{Appendix A. Titles of newspapers (in alphabetical order)}
Aberdeen Press and Journal
Barnesley Star
Bath Chronicle
Belfast Telegraph
Birmingham Post
Blackpool Gazette
Bradford Telegraph and Argus
Bristol Evening Post
BMJ
Burton Daily Mail
Chorley Citizen
Colchester Evening Gazette 
Corby Evening Telegraph

Coventry Evening Telegraph

Craven Herald and Pioneer

Croydon Adviser

Cynon Valley Leader

Daily Mail

Daily Mirror

Daily Post

Daily Record

Daily Telegraph

Darlington and Stockton Times

Derby Evening Telegraph

Doctor

Doncaster Star

Dorsett Evening News

Dundee Courier and Advertiser

East Anglian Daily

Eastern Evening News

Edinburgh Evening News

Evening Echo

Evening Standard

Exeter Express and Echo

The Express

Financial Times

Glasgow Evening Times

The Guardian

Guernsey Press and Star

Halifax Evening Courier

Health and Ageing

Heartland Evening News

The Herald

Herald of Wales

Hospital Doctor

Huddersfield Daily Examiner

The Independent

Ipswich Evening Star

Irish Independent

The Irish Times

Irvine Herald

Irvine Times

Jersey Evening Post

Keighley News

Kentish Express

Kettering Evening Telegraph

Kidderminster Express and Star

Lancashire Evening Post

Leicester Mercury

Leigh Tyldesley and Atherton Journal

Lichfield and Burntwood Express and Star

Lincolnshire Echo

Liverpool Echo

Longride and Ribble Valley News

Maidenhead Advertiser

Manchester Evening News

Manchester Metro News

Manx Independent
Medical Monitor

Metro London

Metro North West

The Mirror

New Scientist

The News

News and Star

Newcastle Upon the Tyne Evening Chronicle

Newcastle Upon the Tyne Journal

North West Evening Mail

Northampton Chronicle and Echo

Northern Echo

Nottingham Evening Post

Nuneaton Evening Telegraph

Nursing Standard

Nursing Times

Oxford Mail

Peterborough Evening Telegraph

The Planet

Plymouth Evening Herald

Practice Nursing

Pulse

Richmond Comet

Rotherham Star

Scarborough Evening News

The Scotsman

Shippy Gazette

Shropshire Star

South Wales Argus

South Wales Echo

South Wales Evening Post

Southern Reporter

Stafford Express and Star

The Star

Swindon Evening Advertiser

The Times

Ulster News Letter

Uxbridge and West Drayton Gazette

Western Daily Press

Western Mail

Western Morning News

Wigan Evening Post

Wolverhampton Express and Star

Yorkshire Evening Press

Yorkshire Evening Post

\section{References}

[1] Gotzsche PC, Olsen O. Is screening for breast cancer with mammography justifiable? Lancet 2000;355(8 January):129 34.

[2] NHS Breast Screening Programme. Analysis of coverage achieved following the paper in Lancet (January 8, 2000): Is mammographic screening for breast cancer justified? Citigate, Westminster.

[3] O'Sullivan R. Women reassured on value of breast screening. The Irish Times (Dublin), 2000 January 7;1. 
[4] Koning HJ. Commentary: assessment of nationwide cancer screen ing programmes. Lancet 2000;355(January 8):80 1.

[5] Irwin A. Breast cancer screening 'is a waste of time'. The Daily Telegraph (Early Edition), 2000 January 7;7.

[6] Murray I. Women urged to ignore cancer report. The Times (Early Edition), 2000 January 8;4.

[7] von Radowitz J. Screening for breast cancer waste of time. Newcastle Upon Tyne Journal, 2000 January 7;4.

[8] von Radowitz J. Shock attack on cancer screening. Nuneaton Evening Telegraph, 2000 January 7;4.

[9] von Radowitz J. Cancer screening is just a waste of time. Daily Post (Wales), 2000 January 7;2.

[10] Munro R. Breast screening unjustified claims study. Nursing Times (Formerly Nursing Mirror), 2000 January 13;8.

[11] Haverty A. Breast screening report attacked. Hospital Doctor, 2000 January $13 ; 7$.
[12] Ong G, Austoker J, Brett J. Breast screening: adverse psychological consequences 1 month after placing women on early recall because of a diagnostic uncertainty. A multicentre study. J Med Screening 1997;4:1 11 .

[13] O'Conner AM, Rostom A, Fiset V, Tetroe J, Entwistle V, Llewellyn Thomas H, et al. Decision aids for patients facing health treatment or screening decisions: a systematic review. BMJ 1999;319:731 4.

[14] Holmes Rovner M, Llewellyn Thomas HA, Entwistle VA, Coulter A, O'Conner A, Rovner DR. Patient choice modules for summaries of clinical effectiveness: a proposal. BMJ 2001;322:664 7.

[15] Deber RB, Kraetschmer N, Irvine J. What role do patients wish to play in treatment decision making? Arch Int Med 1996;156: 141420.

[16] Olsen O, Gotzsche PC. Screening for breast cancer with mammo graphy (Cochrane Review). In: The Cochrane library, Issue 4. Oxford: Update Software; 2001. 